\title{
Bacterial Meningitis
}

National Cancer Institute

\section{Source}

National Cancer Institute. Bacterial Meningitis. NCI Thesaurus. Code C118297.

Inflammation of the membranes surrounding the brain and spinal cord due to a bacterial infection. 